\title{
The influence of acceptance and adoption drivers on smart home usage
}

\section{Article}

Published Version

Creative Commons: Attribution 4.0 (CC-BY)

Open Access

Hubert, M., Blut, M., Brock, C., Zhang, R. W., Koch, V. and Riedl, R. (2019) The influence of acceptance and adoption drivers on smart home usage. European Journal of Marketing, 53 (6). pp. 1073-1098. ISSN 0309-0566 doi: https://doi.org/10.1108/EJM-12-2016-0794 Available at https://centaur.reading.ac.uk/79854/

It is advisable to refer to the publisher's version if you intend to cite from the work. See Guidance on citing.

To link to this article DOI: http://dx.doi.org/10.1108/EJM-12-2016-0794

Publisher: Emerald

All outputs in CentAUR are protected by Intellectual Property Rights law, including copyright law. Copyright and IPR is retained by the creators or other copyright holders. Terms and conditions for use of this material are defined in the End User Agreement.

\section{www.reading.ac.uk/centaur}

\section{CentAUR}

Central Archive at the University of Reading 
Reading's research outputs online 


\section{e emeraldinsight}

\section{European Journal of Marketing}

The influence of acceptance and adoption drivers on smart home usage

Marco Hubert, Markus Blut, Christian Brock, Ruby Wenjiao Zhang, Vincent Koch, René Riedl,

\section{Article information:}

To cite this document:

Marco Hubert, Markus Blut, Christian Brock, Ruby Wenjiao Zhang, Vincent Koch, René Riedl, (2018)

"The influence of acceptance and adoption drivers on smart home usage", European Journal of

Marketing, https://doi.org/10.1108/EJM-12-2016-0794

Permanent link to this document:

https://doi.org/10.1108/EJM-12-2016-0794

Downloaded on: 15 October 2018, At: 07:17 (PT)

References: this document contains references to 70 other documents.

The fulltext of this document has been downloaded 163 times since 2018*

\section{Users who downloaded this article also downloaded:}

(2017),"User acceptance of smart home services: an extension of the theory of planned

behavior", Industrial Management \&amp; Data Systems, Vol. 117 Iss 1 pp. 68-89 <a href="https://

doi.org/10.1108/IMDS-01-2016-0017">https://doi.org/10.1108/IMDS-01-2016-0017</a>

(2017),"The interplay of customer experience and commitment", Journal of Services Marketing, Vol. 31 Iss 2 pp. 148-160 <a href="https://doi.org/10.1108/JSM-09-2016-0337">https://doi.org/10.1108/ JSM-09-2016-0337</a>

Access to this document was granted through an Emerald subscription provided by All users group

\section{For Authors}

If you would like to write for this, or any other Emerald publication, then please use our Emerald for Authors service information about how to choose which publication to write for and submission guidelines are available for all. Please visit www. emeraldinsight.com/ authors for more information.

\section{About Emerald www.emeraldinsight.com}

Emerald is a global publisher linking research and practice to the benefit of society. The company manages a portfolio of more than 290 journals and over 2,350 books and book series volumes, as well as providing an extensive range of online products and additional customer resources and services.

Emerald is both COUNTER 4 and TRANSFER compliant. The organization is a partner of the Committee on Publication Ethics (COPE) and also works with Portico and the LOCKSS initiative for digital archive preservation.

*Related content and download information correct at time of download. 


\title{
The influence of acceptance and adoption drivers on smart home usage
}

\author{
Marco Hubert \\ Aarhus University, Aarhus, Denmark \\ Markus Blut \\ Aston Business School, Birmingham, UK \\ Christian Brock \\ Universität Rostock Wirtschafts und Sozialwissenschaftliche Fakultät, \\ Rostock, Germany \\ Ruby Wenjiao Zhang \\ Newcastle University, Newcastle, UK \\ Vincent Koch \\ Zeppelin University gGmbH, Friedrichshafen, Germany, and \\ René Riedl \\ Johannes Kepler University Linz, Linz, Austria and \\ Upper Austria, University of Applied Sciences, Steyr, Austria
}

\begin{abstract}
Purpose - This study aims to develop a comprehensive adoption model that combines constructs from various theories and tests these theories against each other. The study combines a technology acceptance model, innovation diffusion theory and risk theory. It develops this model in a smart home applications context.
\end{abstract}

Design/methodology/approach - The study is based on an online survey consisting of 409 participants, and the data are analyzed using structural equation modeling.

Findings - Each theory provides unique insights into technology acceptance and numerous constructs are interrelated. Predictors from innovation diffusion and risk theory often display indirect effects through technology acceptance variables. The study identifies risk perception as a major inhibitor of use intention, mediated through perceived usefulness. Results reveal that the most important determinants of use intention are compatibility and usefulness of the application.

Research limitations/implications - Studies which do not examine different theories together may not be able to detect the indirect effects of some predictors and could falsely conclude that these predictors do no matter. The findings emphasize the crucial role of compatibility, perceived usefulness and various risk facets associated with smart homes.

(C) Marco Hubert, Markus Blut, Christian Brock, Ruby Wenjiao Zhang, Vincent Koch and René Riedl. Published by Emerald Publishing Limited. This article is published under the Creative Commons Attribution (CC BY 4.0) licence. Anyone may reproduce, distribute, translate and create derivative works of this article (for both commercial and non-commercial purposes), subject to full attribution to the original publication and authors. The full terms of this licence may be seen at http://creativecommons.org/licences/by/4.0/legalcode 
Originality/value - This study broadens the understanding about the necessity of combining acceptance and adoption drivers from several theories to better understand the usage of complex technological systems such as smart home applications.

Keywords Technology acceptance model, Perceived risk, Innovation diffusion theory, Smart home application

Paper type Research paper

\section{Introduction}

Marketing and information system research has a long history of studying the customer's acceptance and adoption process of new technologies (Moore and Benbasat, 1991; Venkatesh et al., 2003). These studies are often motivated by the potential of new technologies such as smart home systems to improve our everyday life. To benefit from these technologies, individuals have to accept them. In a recent report, McKinsey and Company (2018) indicate that the annual smart home growth in the USA is around 31 per cent with 29 million connected homes in 2017. The report also stresses that "[m]any consumers still do not understand connected device value propositions and early adopters face significant pain points that have yet to be addressed." To better understand the acceptance process, scholars regularly use various theories in their studies, and particularly the technology acceptance model (TAM; Davis, 1989). The explanation of the further adoption process and the related diffusion of new technologies is often based on the innovation diffusion theory (IDT) established by Rogers (2003). Moreover, literature also indicates that perceived risk (PR) plays a crucial role for the acceptance and adoption of new technologies (Featherman and Pavlou, 2003; Wu and Wang, 2005). Although each of these theories provides valuable insights, only recently scholars started combining them in larger framework and examining their interrelationships. These studies argue that each theory has the potential to make a unique contribution to the understanding of technology acceptance; however, the combination of theories leads to novel insights. For instance, TAM suggests that perceived usefulness (PU) of technology and ease of technology use are the key acceptance drivers (Davis, 1989; King and He, 2006). While these factors focus on the evaluation of the individuals' perceived utility and effort of using the technology (Davis, 1989), they do not consider other factors, for instance, the level of innovativeness, the technological components of the innovation and/or social processes (Ward, 2013). Hence, IDT complements our understanding by covering antecedents not being addressed in TAM, such as the observability and trialability of technology, and how these technologies fit into an individuals' lifestyle (Rogers, 2003). Therefore, it is often not possible to explain adoption of technologies based on just a single (theoretical) approach (Benbasat and Barki, 2007). In this context, Lowe and Alpert (2015) particularly stress the importance of theories that consider customer perceptions of the innovation (e.g. PU).

Against this background, the present study intends to contribute to the literature by developing a comprehensive adoption model using key elements of three major theories. The study combines constructs from the TAM (Davis, 1989), the IDT (Rogers, 2003), and the perceived risk theory (PRT; Featherman and Pavlou, 2003). These theories have been chosen for two reasons:

First, among the various models that try to explain the underlying factors of user acceptance of new technologies, the TAM is the most often used theory (Yi et al., 2006), and its predictors are crucial for the acceptance of many technologies (King and He, 2006). Similarly, IDT is a major innovation theory, which is therefore likely to explain technology adoption well. Both theories are also related to each other, as they share the view that the 
adoption of a particular technology is determined by its perceived attributes (Moore and Benbasat, 1991). Combining TAM and IDT would lead to the development of a holistic model that explains a large percentage of variance in intention to use a technology and actual technology usage. Furthermore, in a review of the TAM literature, Benbasat and Barki (2007) criticized that acceptance studies often only focus on TAM without considering other theories due to the dominance of this theory in the literature. They particularly emphasize the changing context of information technology (IT) and stress the importance of risk perceptions associated with these technologies as a fruitful field for theory combination. For this reason, the present research examines risk theory together with IDT and TAM. By combining these theories, the investigated model captures positive (e.g. usefulness of technology, compatibility of a new technology with existing technologies) and negative factors (e.g. perceived security risk) simultaneously. The need for combining acceptance theories in more comprehensive frameworks is also stressed by Venkatesh et al. (2003, p. 426) who argue that "researchers are confronted with a choice among a multitude of models and find that they must 'pick and choose' constructs across the models, or choose a 'favored model' and largely ignore the contributions from alternative models. Thus, there is a need for a review and synthesis to progress toward a unified view of user acceptance."

Second, we have also chosen these theories because of the examined technology. Smart homes are residential buildings, which are equipped with intelligent sensors, lights, heaters and electronic devices based on the anticipated needs of its residents to increase the comfort, entertainment and security (Hoffman and Novak, 2016). These technologies are:

- installed at the user's homes often connected by an internal home network;

- where mobile devices communicate with stationary devices via a home gateway; and

- often use cloud servers for additional smart home services as well as collection and analysis of data from home devices for interactive and automated services (Yang et al., 2017).

These technologies are complex and often difficult to grasp for users, as these innovations are new multifaceted technologies, which build on a combination of already existing and new applications, technologies, services and processes (Tung et al., 2008; Wu et al., 2007). Thus, besides acceptance and adoption processes, risk perceptions may strongly influence the individual's decision when dealing with these technologies (Featherman and Pavlou, 2003). Hence, the adoption decision may not only be influenced by the usefulness of the technology but customers may also perceive the technology to be particularly risky. For example, users may perceive security and performance risks associated with smart homes (Featherman and Pavlou, 2003; Yang et al., 2017). They may not only worry about losing control over personal information when using smart homes and about illegal access by third parties to the system but also worry that the system is flawed and does not work the way it is supposed to. However, most studies on smart home applications examined either only components of a single theory (Balta-Ozkan et al., 2014; Mi and Kim, 2010) or used only selected constructs from different theories together (Shih, 2013; Yang et al., 2017).

Moreover, a better understanding about the interrelationships among the predictors of various theories not only contributes to technology acceptance literature but also provides managers guidance when introducing innovations (Hasan et al., 2017, 2018). This is particularly interesting for smart home technologies, as scholars regularly emphasize that the smart home industry has focused predominantly on the development of technology without paying much attention to the users and their specific needs (Balta-Ozkan et al., 2014; 
Hoffman and Novak, 2016). A comprehensive understanding about the various influencing factors therefore provides managers of smart home and other complex technologies guidance on how to introduce innovations more successfully (Hasan et al., 2017).

The remainder of this paper is structured as follows: After a brief presentation of the theoretical background, research hypotheses are derived, and the conceptual model is introduced. Next, the study presents the results based on a sample of 409 survey participants and theoretical as well as managerial implications were discussed. Finally, the limitations of the study are discussed and avenues for further research are presented.

\section{Theoretical background}

Technology acceptance model

The TAM is tailored to predict and explain users' acceptance of technology (Davis, 1989; Davis et al., 1989). There are two fundamental beliefs in this model, namely, that PU and perceived ease of use (PEOU) primarily determine the attitudes toward technology and the actual acceptance of it. PU focuses on the user's subjective possibility of increasing the performance when adopting a technology, whereas PEOU refers to the user's expectation that using the technology is free of effort. TAM is derived from the theory of reasoned action (Ajzen and Fishbein, 1980) with the attempt to apply psychological factors to the study of information systems (IS; Schepers and Wetzels, 2007). TAM serves as a conceptual basis for IS research and was applied and extended in a variety of contexts (King and He, 2006; Ma and Liu, 2004). This model is one of the most frequently used theoretical frameworks to explain the acceptance of technology (Chang and Wu, 2012; Davis, 1989; Davis et al., 1989; Lee, 2009; Qi et al., 2009; Venkatesh and Davis, 2000). A meta-analysis of 88 studies conducted by King and He (2006) has shown that TAM can be used as a reliable model for predicting the acceptance of technology, and it is widely used to gauge user's perceptions of technology innovation and the probability of acceptance (Moon and Kim, 2001).

\section{Innovation diffusion theory}

While TAM examines various factors explaining technology acceptance such as user demographic and psychographic factors, the factors discussed in IDT focus solely on technology-related determinants (Blut et al., 2016). IDT explains the entire diffusion of innovation process that passes from innovation development to forming the user's attitudes and to the final decision of an adoption or rejection (Moore and Benbasat, 1991; Rogers, 2003). According to Rogers (2003), the diffusion of innovation is a procedural sequence in which an innovation is communicated through certain channels between members of a social system. The rate of diffusion is determined by the rate of adoption, which refers to the relative speed of use by members of the social system (Rogers, 2003). The rate of adoption itself is, in turn, influenced by various attributes of the innovation. Rogers (2003) identified five major attributes, which are relevant from a potential user's perspective: relative advantage, complexity, compatibility (CO), trialability (TRI) and observability of the innovation. Regarding observability, Moore and Benbasat (1991) theorize and also provide empirical evidence that this factor is composed of two dimensions including visibility of the innovation and perceived result demonstrability. The influence of visibility and result demonstrability on the diffusion process has also been shown by numerous other authors (Holak and Lehmann, 1990; Shih, 2013).

\section{Perceived risk theory}

In general, during the decision-making process (i.e. purchase decision), individuals often perceive significant risks (Holak and Lehmann, 1990). The information system and 
consumer behavior literature postulates that PR has an influence on the user's adoption decision of technical innovations. In the field of information system research, PR is captured as the potential loss associated with adoption of technical innovation and acts as an inhibitor to the adoption decision (Featherman and Pavlou, 2003). PR becomes one of the major determinants in influencing individual's acceptance and adoption in circumstances of possible task-related problems, making the user experience uncertainty, discomfort, concerns or anxiety (Featherman and Pavlou, 2003). The PRT is relevant for the present research because the risks of discomfort and uncertainty may be inevitable in smart home usage due to the impersonal and unpredictable nature of intelligent applications (Pavlou, 2003).

\section{Interdependencies between technology acceptance model, innovation diffusion theory and perceived risk constructs}

Despite the paramount importance of the explanation of technology acceptance and adoption in a digital world, literature trying to better explain technology adoption and acceptance by combining TAM and IDT components is limited (Ward, 2013). Existing conceptual frameworks drawing upon TAM and/or IDT are often related to a specific industry (i.e. health sector or logistics; Park and Chen, 2007; Tung et al., 2008; Ward, 2013), have only used selected elements from these theories (Wu and Wang, 2005; Wu et al., 2007) or used elements, which showed a similar meaning and high correlations (i.e. relative advantage and PU) within one model (Lee et al., 2011; Zhou, 2008). Furthermore, research on the combination of IDT and TAM components often neglected the impact of PR, despite the fact that this factor has been identified as important for technology acceptance decisions (Featherman and Pavlou, 2003). Specifically, studies have shown that PR is negatively related to technology usage intention and other mediators within TAM (Pavlou, 2003). Table I provides an overview over initial studies that combine some IDT and TAM components.

\section{Acceptance of smart home technologies}

As aforementioned, smart home applications consolidate a set of different technologies, services and applications within one complex system (Wu et al., 2007; Yang et al., 2017). The connection of several home applications with mobile devices and the connection via home networks allow provision of new services (Wu et al., 2007; Yang et al., 2017). For instance, users may remotely or even automatically start the air conditioner or heater at home, close the blinds and switch on the lights. Balta-Ozkan et al. (2013) identified three main categories of smart home services: lifestyle support services, energy consumption and management services and safety services. Smart home users are therefore confronted with the combination of different technologies with different usage contexts. Research on smart home technology has yet to study the benefits of the technological components and should combine the perceived utility of the smart home technology with the user's evaluation of the technological components and their innovativeness (Rogers, 2003).

However, in the context of smart home applications, most research only focuses on specific acceptance factors (Han and Lim, 2010). To the best of our knowledge, Shih (2013) was one of the first researchers trying to explain the acceptance of smart home systems by using an extended version of TAM. The study demonstrated a relationship between positive attitudes toward smart home systems and the usage of these systems. Nonetheless, this study did not consider PRs associated with smart home systems but recommended to investigate their influence in further research. For the context of smart home applications, risks could either be derived from the technology-based infrastructures (environmental 
EJM

Table I.

Selected integrative studies on TAM and IDT

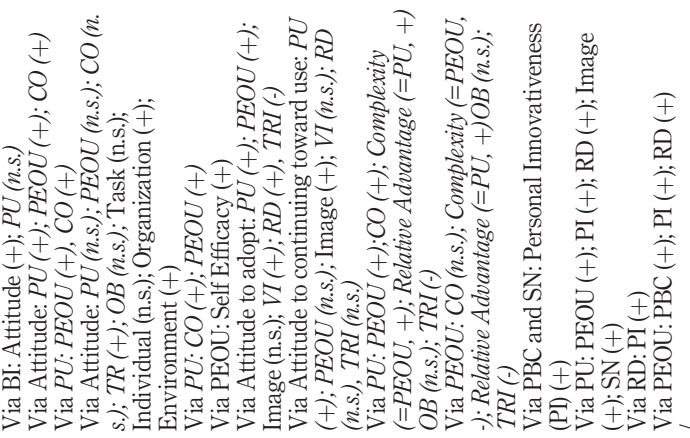

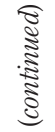

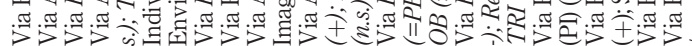

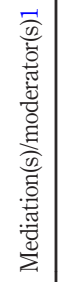

8

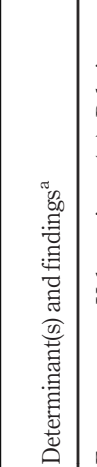

$\checkmark \dot{\hat{\theta}}$

这

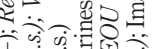

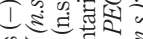

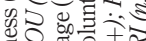

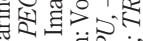

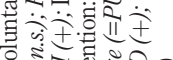

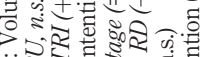

ن․․․

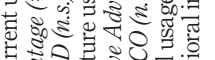

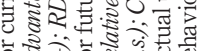

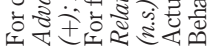

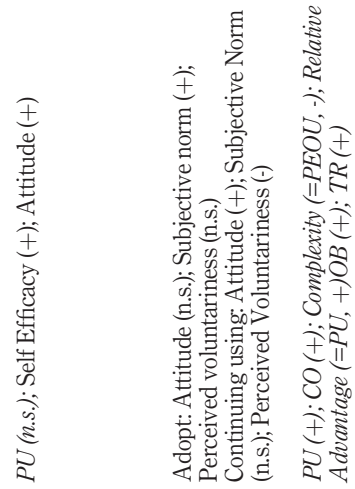

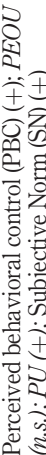

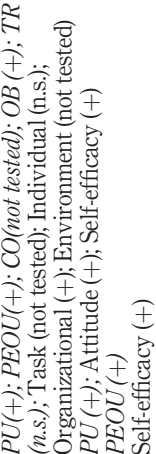

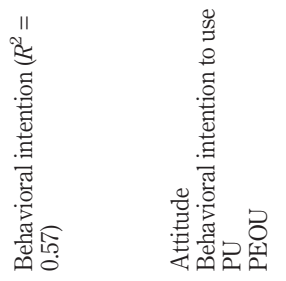

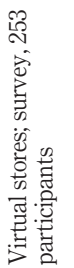

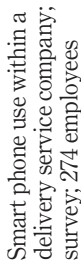

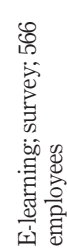

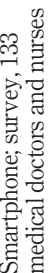

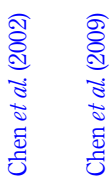

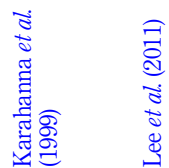

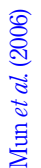

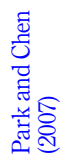




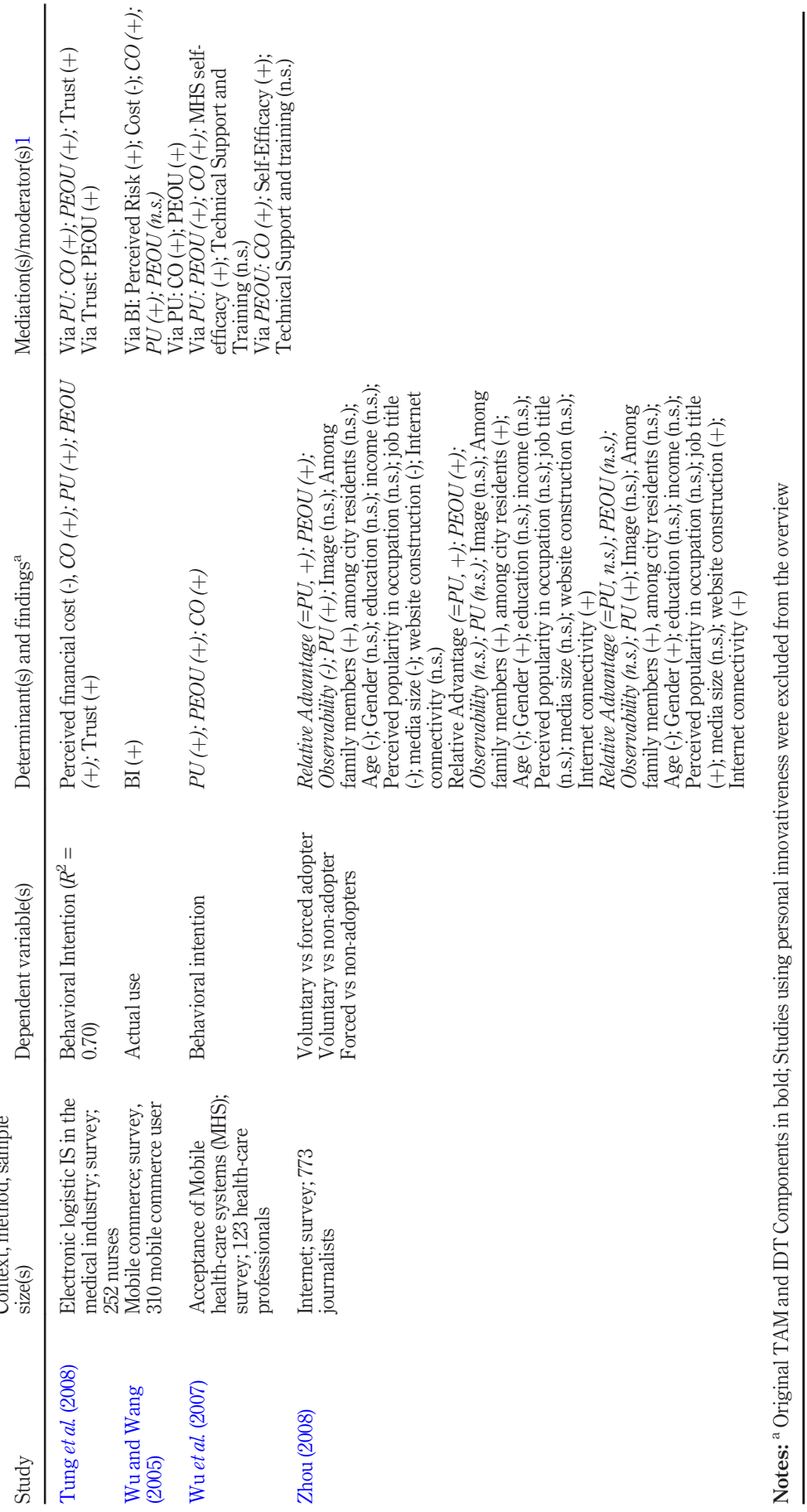

Smart home usage

Table I. 
risks) or resulted from the individuals (behavioral risks) (Ring and Van de Ven, 1994). This is in line with Balta-Ozkan et al. (2014) and Yang et al. (2017) who identified privacy and security concerns as potential risks.

\section{Hypotheses development}

The model in Figure 1 conceptually integrates the existing literature (Table I), and therefore provides a comprehensive picture of established knowledge in the technology acceptance domain, which has not yet been tested empirically in the context of smart home applications. Against this, hypotheses for two research models are developed.

As Figure 1 illustrates, the first set of hypotheses relates to Model 1, which combines IDT and TAM constructs. Thus, hypotheses are derived for the influence of PU and PEOU on usage intention of a smart home application (based on the TAM literature). Moreover, hypotheses are also derived for the influence of CO, TRI, result demonstrability (RD) and visibility (VI) on usage intention (based on the IDT literature). Importantly, these four factors from IDT may exert their influence on usage intention either directly or indirectly via PU and PEOU. It follows that the four IDT attributes (CO, TRI, RD, VI) are conceptualized as independent variables, and the two TAM constructs (PU, PEOU) as mediator variables. Figure 1 also shows that different risk facets are integrated into the model (Model 2), demonstrating the importance of PR to understand technology acceptance decisions (Pavlou, 2003).

\section{Model 1 - technology acceptance model and innovation diffusion theory}

This model is based on the two key factors that affect technology acceptance: PU and PEOU (Davis, 1989). Several meta-analyses on TAM showed that PU is a critical factor of IT acceptance in general; it explains a large proportion of variance of an individual's behavioral intention to use an innovation or (mobile) technology (Hubert et al., 2017; King and He, 2006; Ma and Liu, 2004; Park and Chen, 2007; Qi et al., 2009; Schepers and Wetzels, 2007; Wu and Wang, 2005). The construct of PEOU is related to the users' individual assessment of the effort associated with learning and the perceived usability of a technology (Lee, 2009). According to Chen et al. (2009), high usability does not only influence the intention to accept smartphones but also the perception of their usefulness. Importantly, this and similar research results provide evidence that PEOU both directly and indirectly (via PU) affects usage intention (Davis, 1989; Davis et al., 1989). Additionally, Featherman and Pavlou (2003) have demonstrated that online transactions with a high degree of PEOU are perceived as less risky by potential users. Based on the above arguments, the following hypotheses can be derived:

\section{H1a-b. PU and PEOU positively affect intention to use a smart home application.}

\section{H2. PEOU positively affects PU of a smart home application.}

The present study is based on the following IDT key factors: CO, TRI, RD and VI[1]. Compatibility of an innovation with existing values, experiences, and needs of potential users represents a key aspect of technology acceptance in general (Rogers, 2003). It is assumed that greater compatibility leads to faster rates of adoption. This view is also supported by the technology task fit theory, which assumes that users will use the technology that fits best to their intended use (Röcker, 2010). Holak and Lehmann (1990) underline the importance of compatibility as a major driver of purchasing decisions because individuals generally tend to avoid changes. With regard to trialability, Moore and Benbasat (1991) could not find a statistically significant relationship between testing of an innovation and its adoption in a corporate context. Nonetheless, they assume significant concerns among users in the context of private use of innovations and that trialability would provide clarity regarding the utility of a 
Smart home usage

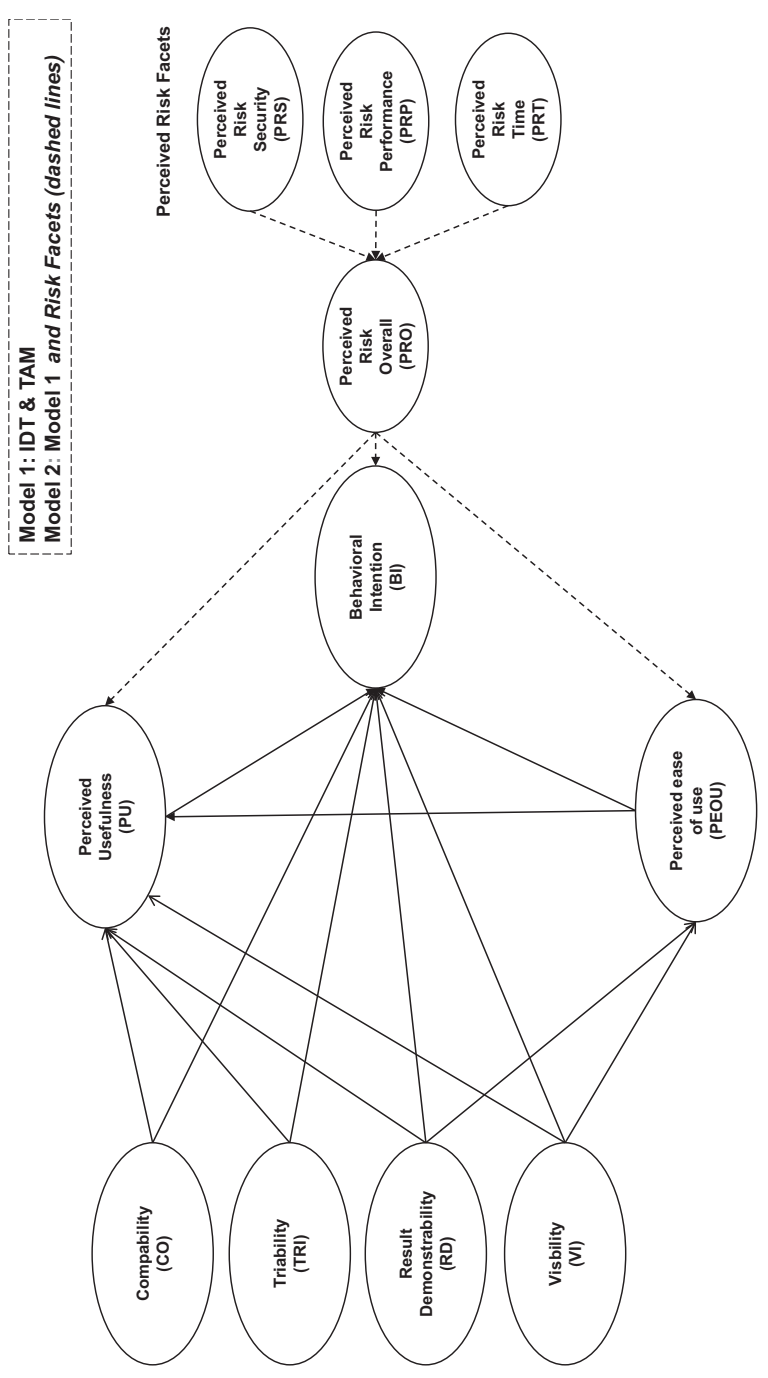

Figure 1. Conceptual model 
technology. Accordingly, the authors recommend including testing opportunity as a potential determinant of adoption decisions in future research models. Chen et al. (2009) found evidence for a relationship between testing of smartphones and associated user attitudes. In addition, Lee et al. (2011) revealed a relationship between the intention to use innovative e-learning systems and the opportunity to test them in advance. In essence, testing of innovations may be positively related to the innovation (Ram, 1987).

Furthermore, it is essential that the results and benefits of the innovation are recognizable to convince potential users. Rogers (2003) refers to the diffusion of mobile phones as a positive example. As this innovation could be observed visually and audiovisually at the beginning of an upcoming popularity, potential users could easily recognize status benefits of the innovation. Adoption of the innovation is, consequently, perceived as less risky. Moore and Benbasat (1991) divided observability into the dimensions of visibility and perceived results demonstrability. Later, the perceived result clarity was included in an extended TAM by Venkatesh and Davis (2000), and its influence on perceived benefits in the context of acceptance of office software was proven. Also, Agarwal and Prasad (1997) observed a significant effect of perceived result demonstrability on the usage intention of the internet in a corporate context. Similarly, visibility was found to have instrumental influence in convincing potential adopters (Agarwal and Prasad, 1997).

We assume that these IDT predictors matter for adoption of smart homes, as smart home systems significantly interfere with the familiar environment of the home. Thus, it can be theorized that users perceive the installation of a smart home system as a significant change in their familiar surroundings; especially when the technology is fully installed at once and not gradually build up over time. Also, similar to the internet in the mid-1990s, smart homes are still a niche market and far from all potential users identified this technology for everyday life. Consequently, the following hypotheses are derived:

H3. The (a) CO, (b) TRI, (c) result demonstrability and (d) visibility related to the smart home application positively affect intention to use this smart home application.

Regarding the interrelationship of IDT and TAM constructs, research shows a fragmented picture (Table I). Some research has shown that CO impacts perceptions of usefulness (Chen et al., 2009; Wu and Wang, 2005) and ease of use (Wu et al., 2007). Additionally, observability and its subcategory result demonstrability (Moore and Benbasat, 1991) were found to influence PU and PEOU (Lee et al., 2011; Mun et al., 2006). Nevertheless, with regard to result demonstrability, trialability and visibility, it is assumed that the opportunity to test the technology prior use provides clarity and therefore positively affects perception of the technological benefits (Lee et al., 2011) as well as the ease of use assessment (Kim and Malhotra, 2005; Ram, 1987). Against this background, a comprehensive model was developed, which considers existing effects of IDT determinants but also addressed neglected effects. Consequently, the following hypotheses were formulated:

H4. The (a) CO, (b) TRI, (c) result demonstrability and (d) visibility related to the smart home application positively affect $\mathrm{PU}$ of this smart home application.

H5. The (a) CO, (b) TRI, (c) result demonstrability and (d) visibility related to the smart home application positively affect PEOU of this smart home application.

\section{Model 2 - the integration of perceived risk facets}

PR plays an important role in the adoption process of new technologies besides the potential benefits associated with these systems (Cho, 2006; Featherman and Pavlou, 
2003; Lee, 2009; Lee and Song, 2013; Pavlou, 2003; Wu and Wang, 2005). For example, studies in a mobile context identified PR as determinant of the acceptance of mobile applications (Bauer et al., 2005; Chan and Chong, 2013; Hubert et al., 2017; Kleijnen et al., 2007; Wu and Wang, 2005).

Based on prior findings, present research proposes that several risk facets may matter in the smart home context (Featherman and Pavlou, 2003; Lee, 2009; Lee and Song, 2013; Yang et al., 2017). Specifically, it is proposed that three specific risk facets are related to this technology. The first specific risk facet is security risk, which refers to the possibility of losing control of personal information (this also includes potential illegal system access from third parties that would cause to fraudulent or criminal activities in and around the house) (Featherman and Pavlou, 2003; Yang et al., 2017). The second specific facet is performance-based risk, which refers to the possibility that the system is flawed and does not work the way it is supposed to and therefore does not provide the originally promised advantages (Featherman and Pavlou, 2003). The third specific facet is time risk, which refers to time loss caused by considerable effort in the decision to purchase, install or repair the system (Featherman and Pavlou, 2003). Additionally, based on existing research overall risk perception, a joint and general measure of PR when all criteria are evaluated together was included as higher-order construct (Featherman und Pavlou, 2003). Therefore, it is hypothesized that:

H6. Perceived specific risk facets of (a) security risk, (b) performance risk and (c) time risk positively affect the perceived overall risk to use a smart home application.

Furthermore, users who assess smart home applications as risky are less likely to use the smart home applications, and it is also less likely that these users assess smart homes applications as useful as indicated by Lee (2009). Furthermore, the greater the PR of smart home applications, the greater the costs and negative utility of using this technology (Kleijnen et al., 2007). Furthermore, customers who have higher risk perceptions might be more demanding with regard to the usability of smart home applications and might be more critical when assessing the system. Consequently, a negative relationship is assumed between the overall risk perception and behavioral intention, PU and PEOU. Thus, the following hypotheses can be derived:

H7. Perceived overall risk negatively affects (a) the behavioral intention, (b) the PU and (c) the PEOU of a smart home application.

\section{Data collection, measurement, and results}

Data collection and study design

To collect the data, a total of 1,780 e-mails were sent referring to an online survey to a random sample of e-mail addresses. These addresses have been extracted from a database administered by the marketing department of a major German university and the SoSciPanel[2]. In total, 409 answered questionnaires were obtained resulting in an overall response rate of 22.98 per cent. To test for nonresponse bias, the answers of early respondents (first one-third of respondents who answered the survey) were compared with late respondents (last one-third) on all the survey items (Armstrong and Overton, 1977). The $t$-test of group means shows no significant differences; thus, it can be concluded that nonresponse bias does not appear to be a problem for this investigation. The extent of common method bias was tested but was not found to be problematic[3]. The sample of the study consists of 205 female and 204 male respondents. Most participants were between 20 and 24 years old (28.4 per cent), followed by the group of 25 to 29 year-olds (16.5 per cent). 
The median was between 30 and 34 years. The respondents indicated that 66.5 per cent of them currently lived in a rented flat/house or shared apartment and 31.5 per cent of the respondents owned their own flat or house at the time of the survey.

Similar to the study from Fang et al. (2005), a scenario-based survey was used to examine the usage intention of the smart home technology. Participants of this study received a link, which referred them to a website and a smart home system was presented before completing the survey. The smart home system described in the scenario was called "Casa Mi" and represents a system prototype. The description of the prototype gives examples of benefits provided by Casa Mi which the potential user may find useful (PU). It is indicated that Casa $\mathrm{Mi}$ allows the user to access information from everywhere which provides feelings of security and comfort. The system sends an alarm in case of an emergency to the user, the police or, in case of fire and smoke, to the firefighters. The sensors recognize leaking water and also inform the user about the arrival of family members. The system informs about weather changes and potential threats of thunder storms and heavy rain, as well as the need to close windows and doors. Regarding PEOU, the description highlights that the prototype includes sensors, which can be installed at home without much effort. The system connects to the smartphone with a specific app (iOS, Android), but it can also be accessed with a PC or Mac. It is indicated that it automatically connects with other devices via Wi-Fi, and it can be installed easily without special tools or equipment. The online scenario was presented to study participants, and they could access an online simulation of Casa Mi simulating the smartphone app, which illustrates the received information. Thereby, the users could try some of the app's functionality. These Web prototypes are frequently used by firms to allow customers to better understand new products at home. As this system constitutes a prototype, the study specifically asked participants about behavioral intentions and not about the actual usage of the smart home system. Experimental studies in IS literature frequently ask study participants about their behavioral intentions after introducing them to a new technology via videos, booklets or internet prototypes (Sheng et al., 2008).

\section{Measurement}

Established measurement scales for the latent constructs were used in this study. The measurement of behavioral intention was taken from Venkatesh and Davis (2000) and the PU, and ease of use measures were adapted from Davis (1989). The measures for the different risk dimensions are based on Featherman and Pavlou (2003). The compatibility, results demonstrability and trialability items are based on Moore and Benbasat (1991); the visibility items are based on Park and Chen (2007)[4]. Also, several control variables were measured. While age and income were directly reported by the respondents, a measure from Bruder et al. (2009) was used to assess an individual's general technology affinity[5].

The reliability of the measurement model was tested using confirmatory factor analysis (Mplus software) and calculated Cronbach's alpha coefficients. All alpha coefficients (AC) and composite reliabilities (CR) exceed the minimum threshold values suggested in the literature $(\mathrm{AC}>0.7, \mathrm{CR}>0.6)$. In addition, discriminant validity of the latent constructs was examined using the criterion proposed by Fornell and Larcker (1981). As all squared correlations among latent variables are smaller than their average variances extracted, discriminant validity was given for all constructs except one. Specifically, the trialability and visibility constructs showed high correlations and, thus, were tested separately in subsequent models. Tables II and III provide an overview over the used measurements of this study and their psychometric properties. 


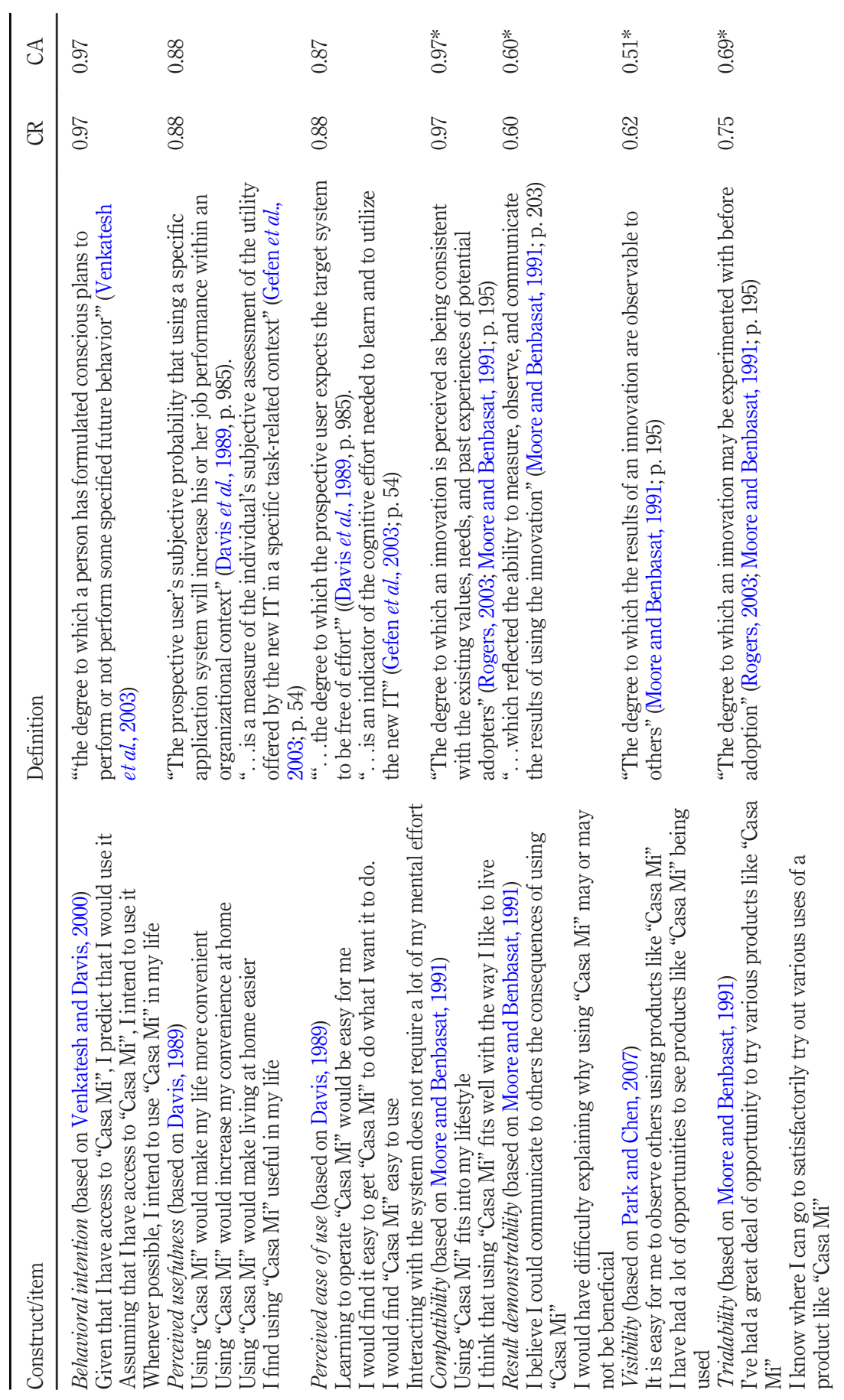

Table II.

Measurement, definitions and psychometric properties 
EJM

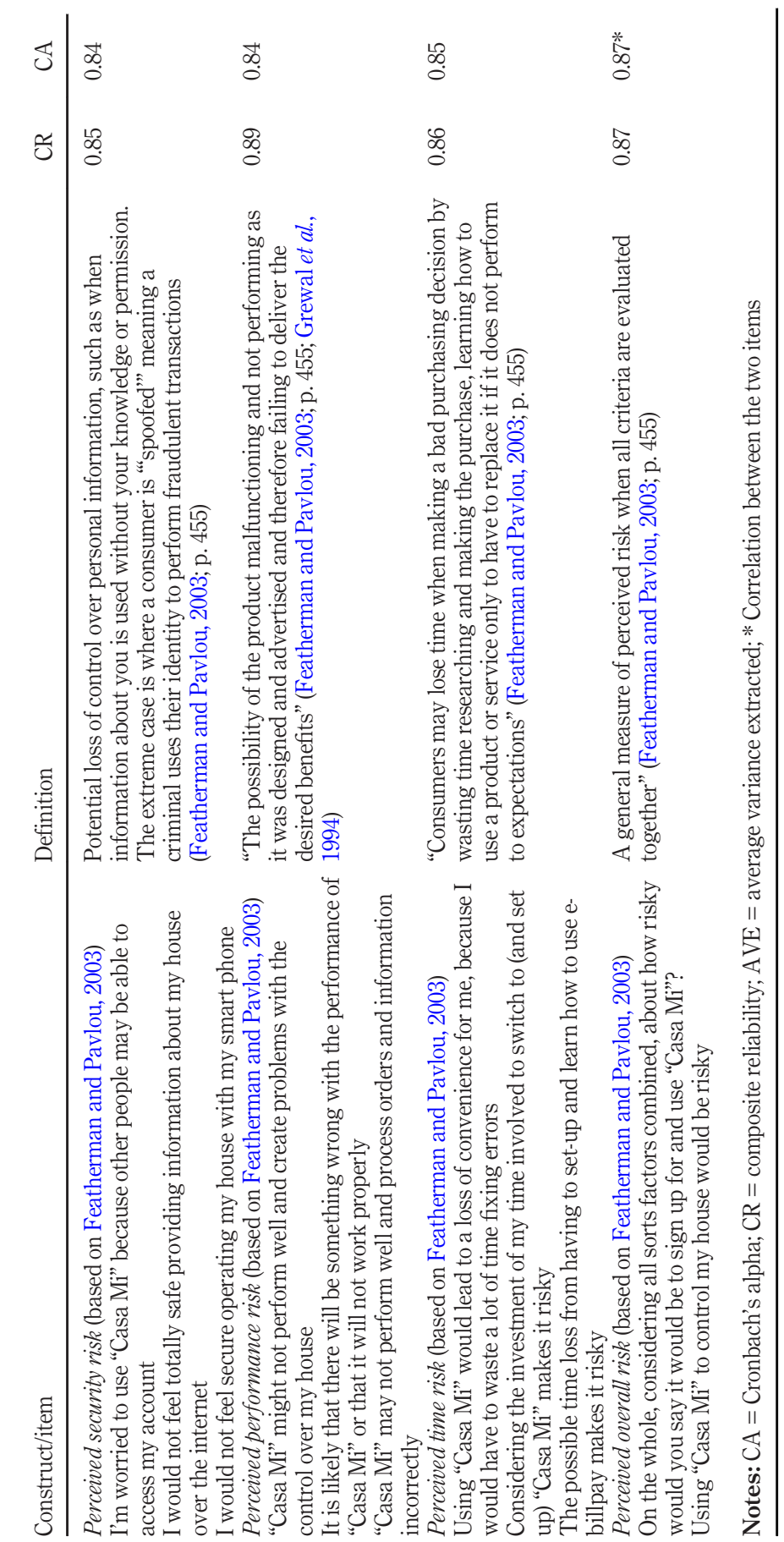

Table II. 


\begin{tabular}{|c|c|c|c|c|c|c|c|c|c|c|c|c|}
\hline & $\mathrm{PU}$ & PEU & PRS & PRP & PRT & PRO & $\mathrm{CO}$ & $\mathrm{RD}$ & VI & TR & BI & thome \\
\hline PU & 1.00 & & & & & & & & & & & \\
\hline PEU & 0.34 & 1.00 & & & & & & & & & & \\
\hline PRS & -0.26 & -0.33 & 1.00 & & & & & & & & & \\
\hline PRP & -0.34 & -0.32 & 0.56 & 1.00 & & & & & & & & \\
\hline PRT & -0.44 & -0.55 & 0.40 & 0.56 & 1.00 & & & & & & & \\
\hline PRO & -0.35 & -0.25 & 0.78 & 0.60 & 0.48 & 1.00 & & & & & & \\
\hline $\mathrm{CO}$ & 0.70 & 0.41 & -0.46 & -0.35 & -0.42 & -0.43 & 1.00 & & & & & \\
\hline $\mathrm{RD}$ & 0.12 & 0.47 & -0.05 & -0.11 & -0.24 & -0.04 & 0.25 & 1.00 & & & & \\
\hline VI & 0.16 & 0.07 & -0.09 & -0.02 & -0.02 & -0.02 & 0.26 & 0.05 & 1.00 & & & \\
\hline TR & 0.18 & 0.08 & -0.07 & -0.05 & -0.03 & -0.01 & 0.27 & 0.05 & 0.98 & 1.00 & & \\
\hline $\mathrm{BI}$ & 0.71 & 0.31 & -0.41 & -0.30 & -0.40 & -0.39 & 0.75 & 0.18 & 0.21 & 0.21 & 1.00 & \\
\hline AVE & 0.66 & 0.65 & 0.65 & 0.73 & 0.67 & 0.77 & 0.95 & 0.43 & 0.49 & 0.61 & 0.92 & \\
\hline
\end{tabular}

Notes: Discriminant validity is given for all construct pairs except for trialibility and visibility. Thus, these two predictors will be tested separately in subsequent models. The high correlation between both constructs is not surprising, as Moore and Benbasat (1991) argue that the different IDT factors are interrelated and some may relate to a higher-order factor

Table III.

Correlations among latent constructs

\section{Results}

The hypotheses of our study were tested using structural equation modeling with Mplus software[6]. The hypotheses were first tested beginning with the model, which includes the constructs suggested by TAM and IDT (Model 1), followed by a model test that also included the additional constructs from PRT (Model 2). We have chosen a step-wise testing approach to better understand how much variance in dependent variables is explained by each theory extension. The two models showed a good overall fit (Model 1: CFI $=0.94$, TLI $=$ $0.92, C h i^{2}=611.66$, RMSEA $=0.06$, SRMR $=0.07$; Model 2: CFI $=0.93$, TLI $=0.92, C h i^{2}=$ 1109.19, RMSEA $=0.05$, SRMR $=0.07$ ).

The test results of Model 1 (Table IV) indicate that 64 per cent of the variance of intention to use smart home systems is explained by TAM and IDT variables. The present study found significant positive effects for $\mathrm{PU}(\beta=0.37, p<0.05 ; H 1 a)$ and compatibility $(\beta=$ $0.46, p<0.05 ; H 3 a)$, while the other variables were not significant $(H 3 b-d)$. Among the tested control variables, only the technology affinity of a smart home customer displayed a significant effect on usage intentions $(\beta=0.11, p<0.05)$. The predictors of PU explain 51 per cent of the variance. As predicted, PEOU $(\beta=0.13, p<0.05 ; H 2)$ and compatibility $(\beta=0.70, p<0.05 ; H 4 a)$ have positive effects on usefulness perceptions. Surprisingly, result demonstrability showed a negative relationship with usefulness perceptions of smart homes $(\beta=-0.14, p<0.05 ; H 4 c)$. Furthermore, the IDT variables explain 36 per cent of the variance in PEOU. While compatibility $(\beta=0.30, p<0.05 ; H 5 a)$ and results demonstrability $(\beta=0.45, p<0.05 ; H 5 c)$ positively impact ease of use perception, which is in line with our predictions, trialability $(H 5 b)$ and visibility $(H 5 d)$ are insignificant.

Results of testing Model 2 indicate that inclusion of risk predictors further improved the model and hence generated additional insights. First, all specific risk facets impact overall risk perceptions with the strongest effect for security risk $(\beta=0.63, p<0.05 ; H 6 a)$, followed by performance risk $(\beta=0.19, p<0.05 ; H 6 b)$ and time risk $(\beta=0.11, p<0.05 ; H 6 c)$. Together these facets explain 66 per cent of variance of overall risk. Second, with regard to the intention to use smart home systems, the full set of predictors explains 65 per cent of the construct's variance, which is only marginally higher than in Model 1 (64 per cent) with significant effects only for $\mathrm{PU}(\beta=0.39, p<0.05 ; \mathrm{H1} a)$ and compatibility $(\beta=0.39, p<$ 
EJM

\begin{tabular}{|c|c|c|c|c|c|c|}
\hline & \multicolumn{3}{|c|}{$\begin{array}{c}\text { Model 1: } \\
\text { TAM/IDT model }\end{array}$} & \multicolumn{3}{|c|}{$\begin{array}{c}\text { Model 2: } \\
\text { TAM/IDT model incl. PRT }\end{array}$} \\
\hline & B & $\mathrm{t}$ & $R^{2}$ & B & $\mathrm{t}$ & $R^{2}$ \\
\hline $\mathrm{PU} \rightarrow \mathrm{BI}(H 1 a)$ & $0.37^{*}$ & 5.57 & 0.64 & $0.39 *$ & 5.59 & 0.65 \\
\hline $\mathrm{PEOU} \rightarrow \mathrm{BI}(H 1 b)$ & -0.04 & -0.73 & & -0.08 & -1.29 & \\
\hline $\mathrm{CO} \rightarrow \mathrm{BI}(H 3 a)$ & $0.46^{*}$ & 7.17 & & $0.39 *$ & 5.58 & \\
\hline $\mathrm{TRI}^{\mathrm{a}} \rightarrow \mathrm{BI}(H 3 b)$ & 0.01 & 0.34 & & 0.02 & 0.58 & \\
\hline $\mathrm{RD} \rightarrow \mathrm{BI}(\mathrm{H} 3 c)$ & 0.01 & 0.09 & & 0.01 & 0.09 & \\
\hline $\mathrm{VI}^{\mathrm{a}} \rightarrow \mathrm{BI}(H 3 d)$ & 0.04 & 0.82 & & 0.04 & 0.89 & \\
\hline $\mathrm{PRO} \rightarrow \mathrm{BI}(H 7 a)$ & & & & 0.02 & 0.18 & \\
\hline $\mathrm{PRS} \rightarrow \mathrm{BI}$ & & & & $-0.16^{*}$ & -1.78 & \\
\hline $\mathrm{PRP} \rightarrow \mathrm{BI}$ & & & & $0.10 *$ & 1.70 & \\
\hline $\mathrm{PRT} \rightarrow \mathrm{BI}$ & & & & -0.07 & -1.10 & \\
\hline \multicolumn{7}{|l|}{ Controlvariables } \\
\hline $\mathrm{TAF} \rightarrow \mathrm{BI}$ & $0.11^{*}$ & 2.14 & & $0.09 *$ & 1.79 & \\
\hline Income $\rightarrow$ BI & -0.02 & -0.59 & & -0.03 & -0.82 & \\
\hline Age $\rightarrow$ BI & 0.04 & 0.97 & & 0.04 & 0.94 & \\
\hline $\mathrm{PEOU} \rightarrow \mathrm{PU}$ (H2) & $0.13^{*}$ & 2.30 & 0.51 & 0.08 & 1.29 & 0.56 \\
\hline $\mathrm{CO} \rightarrow \mathrm{PU}(\mathrm{H} 4 a)$ & $0.70^{*}$ & 10.35 & & $0.68 *$ & 10.33 & \\
\hline $\mathrm{TRI}^{\mathrm{a}} \rightarrow \mathrm{PU}(H 4 b)$ & -0.03 & -0.59 & & -0.02 & -0.36 & \\
\hline $\mathrm{RD} \rightarrow \mathrm{PU}(\mathrm{H} 4 \mathrm{c})$ & $-0.14^{*}$ & -2.01 & & $-0.14^{*}$ & -2.28 & \\
\hline $\mathrm{VI}^{\mathrm{a}} \rightarrow \mathrm{PU}(H 4 d)$ & 0.04 & 0.68 & & 0.04 & 0.72 & \\
\hline $\mathrm{PRO} \rightarrow \mathrm{PU}(H 7 b)$ & & & & $-0.17^{*}$ & -1.76 & \\
\hline $\mathrm{PRS} \rightarrow \mathrm{PU}$ & & & & $0.33^{*}$ & 3.38 & \\
\hline $\mathrm{PRP} \rightarrow \mathrm{PU}$ & & & & $-0.10 *$ & -1.69 & \\
\hline $\mathrm{PRT} \rightarrow \mathrm{PU}$ & & & & -0.11 & -1.50 & \\
\hline $\mathrm{CO} \rightarrow \mathrm{PEOU}(\mathrm{H} 5 a)$ & $0.30 *$ & 5.49 & 0.36 & $0.13^{*}$ & 2.28 & 0.47 \\
\hline $\mathrm{TRI}^{\mathrm{a}} \rightarrow \mathrm{PEOU}(H 5 b)$ & -0.04 & -0.74 & & -0.01 & -0.09 & \\
\hline $\mathrm{RD} \rightarrow \mathrm{PEOU}(H 5 c)$ & $0.45^{*}$ & 5.16 & & $0.33 *$ & 4.64 & \\
\hline $\mathrm{VI}^{\mathrm{a}} \rightarrow \operatorname{PEOU}(H 5 d)$ & -0.07 & 0.94 & & -0.04 & -0.58 & \\
\hline $\mathrm{PRO} \rightarrow \mathrm{PEOU}(H 7 c)$ & & & & $0.23 *$ & 2.14 & \\
\hline $\mathrm{PRS} \rightarrow \mathrm{PEOU}$ & & & & $-0.28^{*}$ & -2.75 & \\
\hline $\mathrm{PRP} \rightarrow \mathrm{PEOU}$ & & & & 0.03 & 0.39 & \\
\hline $\mathrm{PRT} \rightarrow \mathrm{PEOU}$ & & & & $-0.47^{*}$ & -5.75 & \\
\hline $\mathrm{PRS} \rightarrow \mathrm{PRO}(\mathrm{H} 6 a)$ & & & & $0.63 *$ & 10.55 & 0.66 \\
\hline $\mathrm{PRP} \rightarrow \mathrm{PRO}(H 6 b)$ & & & & $0.19 *$ & 2.96 & \\
\hline $\mathrm{PRT} \rightarrow \mathrm{PRO}(H 6 c)$ & & & & $0.11 *$ & 2.01 & \\
\hline CFI & 0.94 & & & 0.93 & & \\
\hline TLI & 0.92 & & & 0.92 & & \\
\hline$C h i^{2}$ & 611.66 & & & 1109.19 & & \\
\hline RMSEA & 0.06 & & & 0.05 & & \\
\hline SRMR & 0.07 & & & 0.07 & & \\
\hline
\end{tabular}

Table IV.

SRMR

Notes: $*=p<0.05$; a due to the high correlation between trialibility (TRI) and visibility (VI), the two predictors have been tested in separate models

$0.05 ; H 3 a)$. Inclusion of risk predictors increased the proportion of variance explained of PU of smart homes, which increased to 56 per cent (Model 1: 51 per cent). Besides compatibility ( $\beta=0.68, p<0.05 ; H 4 a)$ and the opposed effect of result demonstrability $(\beta=-0.14, p<$ $0.05 ; H 4 c)$, impacting usefulness perception, also overall risk $(\beta=-0.17, p<0.05 ; H 7 b)$ was found to exhibit significant influences on PU. Finally, the full set of variables explains 47 per cent of variance of PEOU (Model 1: 36 per cent) with significant effects of compatibility ( $\beta=$ $0.13, p<0.05 ; H 5 a)$ and results demonstrability $(\beta=0.33, p<0.05 ; H 5 c)$, as well as an 
opposed effect of overall risk ( $\beta=0.23, p<0.05 ; H 7 c$ ). The explained variances of Models 1 and 2 display that that combination of TAM/IDT with risk theory is particularly important for better understanding PU and ease of use and less for behavioral intention.

We also calculated the indirect and total effects of various predictors (Table V) and estimated the relative importance of mediators using Alwin and Hauser's (1975) formula. As displayed in Table $\mathrm{V}$, we observe that various predictors influence behavioral intention through examined mediators. The strongest indirect effects were observed for security risk (63 per cent), overall risk (57 per cent) and results demonstrability (50 per cent). Additionally, we found that perceived security risk negatively affects behavioral intention $(\beta=-0.16$, $p<0.05)$ and PEOU ( $\beta=-0.28, p<0.05)$ but positively impacts $\mathrm{PU}(\beta=0.33, p<0.05)$; perceived performance risk positively impacts usage intention $(\beta=0.10, p<0.05)$ but negatively impacts $\mathrm{PU}(\beta=-0.10, p<0.05)$; and perceived time risk negatively influences $\operatorname{PEOU}(\beta=-0.47, p<0.05)$.

\section{Discussion}

The present study intended to develop a comprehensive adoption model combining constructs from three key theories - TAM, IDT and PRT - for two main reasons. First, despite some merits on explaining individuals' behavior (Lee et al., 2011; Moore and Benbasat, 1991, Venkatesh et al., 2003), a structured combination of different constructs related to these theories is lacking, although researchers are frequently encouraged to expand our understanding about TAM by merging it with further theories (Benbasat and Barki, 2007; Venkatesh et al., 2003; Ward, 2013). Second, especially the complexity of a multifaceted technology (Tung et al., 2008; Wu et al., 2007) like a smart home system with its different technologies for different use contexts (Yang et al., 2017) calls for a combination of different theories to better explain adoption behavior.

Results of the present study suggest that the holistic model explains usage behavior well and variables from various theories seem to be related to each other. The interrelationships were tested in two models. While Model 1 captures the positive acceptance factors proposed by TAM and IDT, Model 2 also incorporates the negative factors proposed by risk theory. In Model 1, it was theorized that the acceptance of smart home systems is largely influenced by the PU and PEOU of the technology as suggested by TAM. The model then combined TAM with innovation attributes (described by IDT) and assumed IDT constructs to exert an

\begin{tabular}{|c|c|c|c|c|c|c|c|c|c|c|c|c|}
\hline \multirow{3}{*}{$\begin{array}{l}\text { PU } \\
\text { PEOU }\end{array}$} & \multicolumn{3}{|c|}{$\begin{array}{l}\text { Behavioral intention } \\
\text { Direct Indirect Total }\end{array}$} & rel. Imp. & \multicolumn{3}{|c|}{ Perceived usefulness } & \multicolumn{5}{|c|}{ Perceived ease of use } \\
\hline & 0 & - & $0.39 *$ & & & & & & & & & \\
\hline & -0.08 & 0.03 & -0.05 & 38 & 0.08 & - & 0.08 & & & & & \\
\hline $\mathrm{CO}$ & $0.39 *$ & $0.36^{*}$ & $0.65^{*}$ & 36 & $0.68 *$ & 0.01 & $0.69 *$ & 1 & $0.13^{*}$ & - & $0.13^{*}$ & - \\
\hline $\mathrm{RD}$ & 0.01 & $-0.07^{*}$ & -0.07 & 50 & $-0.14^{*}$ & 0.03 & $-0.11^{*}$ & 21 & $0.33^{*}$ & - & $0.33^{*}$ & - \\
\hline TRI & 0.02 & -0.01 & 0.02 & 33 & -0.02 & -0.00 & -0.02 & 0 & -0.00 & - & -0.00 & - \\
\hline CVI & 0.04 & 0.02 & 0.06 & 25 & 0.04 & -0.01 & 0.04 & 20 & -0.04 & - & -0.04 & - \\
\hline $\mathrm{PRO}$ & 0.02 & $-0.08^{*}$ & -0.06 & 57 & $-0.17^{*}$ & 0.02 & -0.15 & 12 & $0.23^{*}$ & - & $0.23^{*}$ & - \\
\hline PRS & $-0.16^{*}$ & 0.1 & -0.06 & 63 & $0.33^{*}$ & $-0.12^{*}$ & $0.21^{*}$ & 36 & $-0.28^{*}$ & $0.14^{*}$ & $-0.13^{*}$ & 52 \\
\hline PRP & $0.10^{*}$ & $-0.05^{*}$ & 0.04 & 56 & $-0.1^{*}$ & -0.03 & $-0.13^{*}$ & 19 & 0.03 & $0.04^{*}$ & 0.07 & 36 \\
\hline PRT & -0.07 & -0.03 & $-0.10^{*}$ & 23 & -0.11 & -0.06 & $-0.16^{*}$ & 27 & $-0.47^{*}$ & 0.03 & $-0.44^{*}$ & 6 \\
\hline
\end{tabular}

Notes: We calculated the mediation effect using the Alwin and Hauser's (1975) formula of the relative importance: $\mid$ indirect effect $\mid /(\mid$ indirect effect $|+|$ total effect $\mid)$

Smart home usage

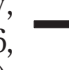


influence on the intention to use smart home applications, and the influence is assumed to be mediated by PU and PEOU. In Model 2, risk factors as potential inhibiting factors were also incorporated. It was proposed that overall PR exerts a negative influence on the behavioral intention of potential users to use smart homes, which is also assumed to be mediated by PU and ease of use. The results of the analyses show that the developed acceptance model explains a large proportion of the dependent variable's variance. This finding supports the assumption of Benbasat and Barki (2007) that holistic models are more likely to fully explain the user's acceptance behavior.

Comparing the results of both models, Models 1 and 2, it was also observed that the overall risk predictor helps explaining variance in the model, and they have strong indirect effects particularly on usage intention through usefulness and ease of use perceptions. Furthermore, security risk is the strongest predictor of the overall risk perception as well as the overall risk perception displays differential effects in Model 2. While overall risk has the intended negative effect on the perception of a smart home's usefulness, it improves a customer's ease of use perception. In summary, the empirical findings show that the expected relationships among the model constructs are in line with most hypotheses (see Table VI for a summary of results of hypotheses testing).

With regard to the TAM and IDT constructs, the strong positive effect of PU on behavioral intention in both models is in line with results of previous studies in the field. Similar to office software (Davis et al., 1989), e-commerce as well as m-commerce (Hubert et al., 2017) or online financial services (Featherman and Pavlou, 2003), the results demonstrate that PU is also a strong predictor of usage intention in the context of smart home systems. The TAM metaanalysis conducted by King and He (2006) confirmed the importance of perceived benefits in technology acceptance. With respect to PEOU, both models showed only an indirect effect on behavioral intention mediated by PU, which is also in line with prior research on TAMs (King and He, 2006) and research at the nexus of TAM and IDT (Chen et al., 2002, 2009; Lee et al., 2011). The present study shows that despite the known multiple benefits and possibilities of smart home applications (Yang et al., 2017), the correct and concrete communication of the benefits of a system is essential. However, because of the use of already experienced technologies (i.e. interface of mobile devices) to communicate with the multifaceted technology (Yang et al., 2017), PEOU seems to be an inferior antecedent.

Among all the IDT factors, compatibility has a strong impact on behavioral intentions, comparable to the influence of PU (Lee et al., 2011; Wu et al., 2007). In addition, compatibility

Table VI.

Overview of supported and nonsupported hypotheses
H1a-b Perceived usefulness and perceived ease of use positively affect intention to use a smart home application

H2 Perceived ease of use positively affects perceived usefulness of a smart home application

H3a-d The a) compatibility, b) triability, c) result demonstrability, and d) visibility related to the smart home application positively affect intention to use this smart home application

H4a-d The a) compatibility, b) triability, c) result demonstrability and d) visibility related to the smart home application positively affect perceived usefulness of this smart home application

H5a-d The a) compatibility, b) triability, c) result demonstrability, and d) visibility related to the smart home application positively affect perceived ease of use of this smart home application

H6a-c Perceived specific risk facets of a) security risk, b) performance risk, c) time risk positively affect the perceived overall risk to use a smart home application

H7a-d Perceived overall risk negatively affect a) the behavioral intention, b) the perceived usefulness and c) the perceived ease of use of a smart home application

Notes: italic $=$ supported hypothesis; bold/italics $=$ significant but reverse effect 
shows a strong positive influence on usefulness and ease of use perceptions (Tung et al., 2008; Lee et al., 2011). Accordingly, a reconciliation of the compatibility of smart home application and the lifestyles of potential users is essential. Compatibility has been found in other studies as an important predictor of technology acceptance (Holak and Lehmann, 1990; Lee et al., 2011), and the effect in the present study is also very strong. Bearing in mind that the use of smart home applications involves a distinct change in the familiar surroundings of home for example due to the use of mobile devices to communicate with stationary devices or the necessary acceptance of cloud servers for data collection and automated services (Yang et al., 2017 - the result seems to be plausible. The strong impact of compatibility on the perceived benefits shows that users want products that facilitate and improve their life but without causing major changes in their usual environment and lifestyle. If the smart home application has a high compatibility with existing values and experiences, changes are perceived less strongly, uncertainties are reduced and behavioral intention as well as PU and ease of use increase.

With regard to the other IDT constructs, result demonstrability only showed a significant effect on PU and PEOU. While the strong positive effect on PEOU is in line with the hypothesis and existing literature (Mun et al., 2006), the negative effect on PU is counterintuitive. It seems that the perceived ability to communicate the value of the smart home system leads to a better self-perception of the ease of use (Kim and Malhotra, 2005; Ram, 1987) but worsens the perception of PU. An explanation for this phenomenon could be going along with the possible complexity of the smart home applications (Yang et al., 2017). We assume that the complexity of technological features is closely related to communication issues, which means that it is more difficult to communicate the benefits of different technological features, which in consequence negatively affect usefulness perceptions. Furthermore, trialability and visibility showed no effect, neither directly on the intention to use a smart home application nor an indirect effect via PU and PEOU. This is in line with the existing literature (Holak and Lehmann, 1990; Moore and Benbasat, 1991) but also an indicator that users need to test an innovation prior to adaptation, and they seem to have problems evaluating a prototype properly that has not been tested in practice by themselves (Karahanna et al., 1999; Kim and Malhotra, 2005; Lee et al., 2011). Thus, these factors should be re-investigated with additional indicators in an independent sample.

With regard to the integration of the different risk facets in the model (Model 2), this research demonstrated that perceived overall risk is composed of different categories of risk (security, performance and time risk). It shows that especially security risk is a strong predictor of the overall risk perception followed by performance and time risk. This result generally confirms existing research on the perceived importance of data security on individuals' adoption decision with regard to complex digital technologies (Baltan-Ozkan et al., 2014; Yang et al., 2017). Especially for a smart home application based on safety improvements, the knowledge about data use and security is an important antecedent of an overall risk perception.

Furthermore, the results indicate that overall risk perception is an important antecedent of technology acceptance in general. Although overall risk perception has no direct effect on behavioral intention, it did influence acceptance indirectly via PU. The higher the perceived overall risk perception, the lower the PU. Consequently, overall risk perception as a perceived subjective combination of different risk facets can act as a critical barrier of adoption and should be deliberately considered in the development and introduction of new multifaceted systems. These relationships are consistent with the results of previous studies (Featherman and Pavlou, 2003; Lee, 2009; $\mathrm{Wu}$ and Wang, 2005). Nevertheless, some findings were contrary to our predictions. 
Particularly, the study found a positive effect of overall risk on PEOU. With regard to this effect, which is partly in line with existing literature (Wu and Wang, 2005), it is assumed that a reason for the observed positive effect could be a stronger salience effect. Especially for applications with a high extent of control, the salience of risk increases for different outcomes and therefore customers will have a higher awareness and rational evaluation of a technology, its features and potential problems, which consequently could lead to a positive evaluation of these above perceptions (Blut $e$ t al., 2016; Hubert et al., 2017).

Besides the assumed direct and indirect effect (Table VI), it was also observed that the different risk facets varied regarding their weight and the direction of their direct influence on behavioral intention, PU and PEOU (Wu and Wang, 2005). A negative direct effect was found for security risk on behavioral intention and PEOU, performance risk on PU and time risk on PEOU. Thus, uncertainties with regard to security, performance and time convenience reduce not only potential antecedents of usefulness (performance risk) and usability of smart home systems (security and time risk) but also the intention to accept and adopt (security risk) directly. It follows that uncertainty reduction with regard to a specific risk perception and in relation to the applied technology is a critical component of improved innovation adoption rates because they have been shown to mitigate, or even eliminate, the fear of users in dealing with the operation and handling of unknown technologies (Rogers, 2003). Additionally, a positive direct effect of performance risk on behavioral intention and security risk on PU was observed, which is again partly in line with the existing literature (Wu and Wang, 2005) and the discussed salience effect (Blut et al., 2016; Hubert et al., 2017).

All in all, the present study showed the importance of comparing and combining different theories and models to generate new insights, which would not have been discovered when examining each theory alone [Benbasat and Barki, 2007; Hasan et al., 2017; 2018; Venkatesh et al., 2003; see also Lowe and Alpert (2015) for a comprehensive framework on consumer innovativeness]. The results indicate that variables of risk theory and IDT often display indirect effects on usage intentions through TAM variables. These effects would not have been detected in single theory studies and researchers would have falsely underestimated the importance of these predictors. For example, the research showed indirect effects of risk perception on the intention to use, mediated by PU. PEOU seems to be not as important as IDT components like compatibility, which directly explain acceptance and adoption intention. Existing theories such as technology acceptance theory are therefore advised to be extended. These studies should also assess whether the specific technology is compatible with other technologies that the user already uses as part of his/her lifestyle. It would be interesting to examine how users deal with potential lifestyle inconsistencies across technologies. Venkatesh et al. (2016) encourage scholars to study more contextual factors when applying and extending technology acceptance theory and consider which predictors to include depending on the study context.

\section{Managerial implications}

To sum up, the present study revealed the necessity of a comprehensive adoption model by combining constructs from acceptance, adoption and risk theories and models to investigate complex multifaceted technologies like smart home applications (Venkatesh et al., 2003; Yang et al., 2017). Furthermore, the study revealed potential barriers of acceptance of smart home applications and identified relevant drivers of perception among potential users. The study identified risk perception as a key barrier hindering the acceptance and adoption of smart homes. Risk perceptions seem to primarily act as an indirect inhibitor of behavioral intention due to its indirect influence through $\mathrm{PU}$ and PEOU. The study also reveals that the 
most important factors and most relevant aspects are compatibility and PU of the smart home technology. Both factors displayed a strong influence on the intention to use smart home systems. From a managerial perspective, the findings emphasize the crucial role of compatibility as well as PU and different facets of risk. Due to the impact of compatibility and PU on behavioral intention, managers should communicate the benefits of using smart home systems toward potential customers. Customers need to be convinced of the value and benefits that make things easier and more convenient at home. Therefore, marketing measures should especially focus on this customer segment. In line with Featherman and Pavlou (2003), the study suggests that managers should control for risk perception and if necessary implement measures to reduced specific (perceived) risk facets. In the present case, it would be helpful to implement measures, such as trustworthy information about the service, satisfaction guarantees and 24/7 services, reducing perceived performance risk and overall risk perception.

\section{Conclusion, limitations and further research}

Despite these new insights into the importance of theory combination and smart home acceptance, the study has some limitations that could be addressed in future research. First, despite the already considerable explained variance, an extension of the overall model with additional factors and variables could increase the explanatory power of the model. One aspect could be an investigation of subjective norms on adoption probability (Venkatesh et al., 2003), perceived novelty (Wells et al., 2010) or factors of innovation resistance (Ram and Sheth, 1989). Prices are also part of the adoption process, as well as quality and value. If these aspects are in a mismatch (i.e. poor price-performance ratio), the technology is not purchased or used. Future studies should use products whose prices are known or estimated to integrate them into the model. Future experimental studies could manipulate the price level and examine the role of pricing for smart home acceptance. Thereby, existing acceptance theories could be expanded with regard to inclusion of price variables. Second, the formed risk construct does not cover all existing types of risk. It is conceivable, where appropriate, to enhance the risk by socio-psychological and financial risks. Third, the object in this study, called "Casa Mi" is a security assistant and a prototype product, which does not yet exist in the real market. In subsequent studies, products should be chosen that are already available for purchase. While experimental studies have the advantage of controlling the influence of various external factors, one has to mention that examination of existing products is important as self-reported intentions are not the same as actual behavior. Future studies are encouraged to conduct more field studies examining actual usage of real products. Fourth, a comparison of different smart home systems could be considered given that smart home systems may serve different user needs (e.g. security versus health needs). One could speculate that, for instance, risk perceptions are even more important for smart security systems, which are mainly developed to make people feel safe, and smart health systems, which have to deal with people's fears of becoming sick. Thus, it is surmised that a smart home system application type moderates relationships in the theoretical model. Finally, it could be interesting to examine acceptance in a cross-cultural setting (Straub et al., 1997). The question whether this general effect also applies to the acceptance of smart home systems could be examined in future research.

\section{Notes}

1. According to existing literature, the IDT is not directly related to the TAM, but both include several similar constructs. It has been established in numerous studies that (a) comparative/ 
relative advantage largely matches with the perceived usefulness construct and that (b) complexity is an inverse factor of the perceived ease of use construct (Moore and Benbasat, 1991). Thus, we do not include relative advantage and complexity in our model in addition to usefulness and ease of use. Instead, we include the more distinct IDT constructs.

2. The SoSci database is a panel open for scholars in social sciences. It includes 87,409 registered panel members from Germany. The panel has the following age distribution: 18-19 years $(2 \%)$, 20-29 (33\%), 30-39 (24\%), 40-49 (14\%), 50-59 (17\%) and 60+ years (11\%). The sample consists of members with diverse educational backgrounds. Asking members about their highest educational qualification, $17 \%$ indicated to have some high school experience, $37 \%$ have a high school degree, and $46 \%$ are college graduates. Due to the diversity of the database, it is frequently used by social science scholars. Since 2010, the panel has been used for 233 research projects.

3. The potential for common method bias was assessed in two ways. First, CFA approach to Harmon's one-factor test is used (McFarlin and Sweeney, 1992). The fit is considerably worse for the unidimensional model than for the measurement model $\left(\Delta \chi^{2} \mathrm{df}=5,165, p<0.05\right)$. Second, the study uses the marker variable technique (Lindell and Whitney 2001). As the marker variable (income) is not significantly related to any of the variables in the model, common method variance is not a serious problem. As suggested by Podsakoff $e t$ al. (2003), potential common method bias was addressed when designing the study, for instance, by varying scale endpoints and formats, reassuring respondents about anonymity of answers and using established measurements.

4. The items of trialability and visibility refer to "products like "Casa Mi"' as the displayed technology is not market-ready yet and only exists as a prototype. Some smart home technologies are already available in some households (e.g. Google's Home) and are already advertised by companies. We therefore asked participants about their opportunities to test and try similar smart home technologies.

5. Testing of income as control variable is important, as the study participants may be worried about the price of the smart home technology. The available monthly income ranged from around 500 Euros to more than 4,000 Euros in our sample. If study participants would expect the price to be too high, one would expect differences in the acceptance of users with different incomes. As income did not correlate with any variable in our model $(\phi>0.05)$, we assume that pricing concerns are less significant.

6. Each construct in our model was measured with at least two items to ensure model identification, according to the two-indicator rule (Kline, 2015). Bollen and Davis (2009) stress that models can be identified even with just one item depending on the number of directed paths emitted by a latent variable ( $2+$ emitted paths).

\section{References}

Agarwal, R. and Prasad, J. (1997), "The role of innovation characteristics and perceived voluntariness in the acceptance of information technologies", Decision Sciences, Vol. 28 No. 3, pp. 557-582.

Ajzen, I. and Fishbein, M. (1980), Understanding Attitudes and Predicting Social Behavior, Prentice-Hall, Englewood Cliffs, NJ.

Alwin, D.F. and Hauser, R.M. (1975), "The decomposition of effects in path analysis", American Sociological Review, Vol. 40 No. 1, pp. 37-47.

Armstrong, J.S. and Overton, T.S. (1977), "Estimating nonresponse bias in mail surveys", Lournal of Marketing Research, Vol. 14 No. 3, pp. 396-402.

Balta-Ozkan, N., Boteler, B. and Amerighi, O. (2014), "European smart home market development: public views on technical and economic aspects across the United Kingdom, Germany and Italy", Energy Research and Social Science, Vol. 3, pp. 65-77. 
Balta-Ozkan, N., Davidson, R., Bicket, M. and Whitmarsh, L. (2013), "Social barriers to the adoption of smart homes", Energy Policy, Vol. 63, pp. 363-374.

Bauer, H.H., Barnes, S.J., Reichardt, T. and Neumann, M.M. (2005), "Driving consumer acceptance of mobile marketing: a theoretical framework and empirical study", Journal of Electronic Commerce Research, Vol. 6 No. 3, pp. 181-192.

Benbasat, I. and Barki, H. (2007), “Quo vadis TAM?", Lournal of the Association for Information Sustems, Vol. 8 No. 4, p. 7.

Blut, M., Wang, C. and Schoefer, K. (2016), "Factors influencing the acceptance of self-service technologies: a Meta-analysis", _ournal of Service Research, Vol. 19 No. 4, pp. 396-416.

Bollen, K.A. and Davis, W.R. (2009), "Two rules of identification for structural equation models", Structural Equation Modeling: A Multidisciblinarv Journal, Vol. 16 No. 3, pp. 523-536.

Bruder, C., Clemens, C., Glaser, C. and Karrer-Gauß, K. (2009), "TA-EG - fragebogen zur erfassung von technikaffinität", FG Mensch-Maschine Systeme TUBerlin.

Chan, F. and Chong, A. (2013), "Analysis of the determinants of consumers' m-commerce usage activities”, Online Information Review, Vol. 37 No. 3, pp. 443-461.

Chang, M.-L. and Wu, W.-Y. (2012), "Revisiting perceived risk in the context of online shopping; an alternative perspective of decision-making styles", Psychology and Marketing, Vol. 29 No. 5, pp. 378-400.

Chen, L., Gillenson, L. and Sherrell, L. (2002), "Enticing online consumers: an extended technology acceptance perspective", Information and Management, Vol. 39 No. 8, pp. 709-719.

Chen, J.V., Yen, D.C. and Chen, K. (2009), "The acceptance and diffusion of the innovative smart phone use: a case study of a delivery service company in logistics", Information and Management, Vol. 46 No. 4, pp. 241-248.

Cho, V. (2006), "A study of the roles of trusts and risks in information-oriented online legal services using an integrated model", Information and Management, Vol. 43 No. 4, pp. 502-520.

Davis, F.D. (1989), "Perceived usefulness, perceived ease of use, and user acceptance of information technology", MIS Quarterly, Vol. 13 No. 3, pp. 319-340.

Davis, F.D., Bagozzi, R.P. and Warshaw, P.R. (1989), "User acceptance of computer technology; a comparison of two theoretical models", Management Science, Vol. 35 No. 8, pp. 982-1003.

Fang, X., Chan, S., Brzezinski, J. and Xu, S. (2005), "Moderating effects of task type on wireless technology acceptance", Lournal of Management Information Sustems, Vol. 22 No. 3, pp. 123-157.

Featherman, M.S. and Pavlou, P.A. (2003), "Predicting e-services adoption: a perceived risk facets perspective", International Journal of Human-Computer Studies, Vol. 59 No. 4, pp. 451-474.

Fornell, C. and Larcker, D.F. (1981), "Evaluating structural equation models with unobservable variables and measurement error", Journal of Marketing Research, Vol. 18 No. 1, pp. 39-50.

Gefen, D., Karahanna, E. and Straub, D.W. (2003), "Trust and TAM in online shopping: an integrated model”, MIS Quarterlv, Vol. 27 No. 1, pp. 51-90.

Grewal, D., Gotlieb, J. and Marmorstein, H. (1994), "The moderating effects of message framing and source credibility on the price-perceived risk relationship", Lournal of Consumer Research, Vol. 21 No. 1, pp. 145-153.

Han, D.M. and Lim, J.H. (2010), "Design and implementation of smart home energy management systems based on zigbee", IEEE Transactions on Consumer Electronics, Vol. 56 No. 3, pp. 1417-1425.

Hasan, M.R., Lowe, B. and Petrovici, D. (2017), “Antecedents of adoption of pro-poor innovations in the bottom of pyramid: an empirical comparison of key innovation adoption models - an abstract", Marketing at the Confluence between Entertainment and Analvtics, Springer, Cham, pp. 1081-1082. 
Hasan, R., Lowe, B. and Petrovici, D. (2018), "An empirical comparison of consumer innovation adoption models: implications for subsistence marketplaces", Iournal of Public Policy and Marketing. Forthcoming.

Hoffman, D.L. and Novak, T.P. (2016), "How to market the smart home: focus on emergent experience, not use cases", available at: https://ssrn.com/abstract=2840976 (accessed 27 December 2016).

Holak, S.L. and Lehmann, D.R. (1990), "Purchase intentions and the dimensions of innovation: an exploratory model”, Journal of Product Innovation Management, Vol. 7 No. 1, pp. 59-73.

Hubert, M., Blut, M., Brock, C., Backhaus, C. and Eberhardt, T. (2017), "Acceptance of smartphone-based mobile shopping: mobile benefits, customer characteristics, perceived risk and the impact of application context", Psychology and Marketing, Vol. 34 No. 2, pp. 175-194.

Karahanna, E., Straub, D.W. and Chervany, N.L. (1999), "Information technology adoption across time: a cross-sectional comparison of pre-adoption and post-adoption beliefs", MIS Quarterly, Vol. 23 No. 2, pp. 183-213.

Kim, S.S. and Malhotra, N.K. (2005), "A longitudinal model of continued IS use: an integrative view of four mechanisms underlying postadoption phenomena”, Management Science, Vol. 51 No. 5 , pp. 741-755.

King, W.R. and He, J. (2006), “A Meta-analysis of the technology acceptance model”, Information and Management, Vol. 43 No. 6, pp. 740-755.

Kleijnen, M., De Ruyter, K. and Wetzels, M. (2007), "An assessment of value creation in mobile service delivery and the moderating role of time consciousness", Lournal of Retailing, Vol. 83 No. 1, pp. 33-46.

Kline, R.B. (2015), Principles and Practice of Structural Equation Modeling, Guilford publications, New York, London.

Lee, M.-C. (2009), "Factors influencing the adoption of internet banking: an integration of TAM and TPB with perceived risk and perceived benefit", Electronic Commerce Research and Applications, Vol. 8 No. 3, pp. 130-141.

Lee, Y.H., Hsieh, Y.C. and Hsu, C.N. (2011), "Adding innovation diffusion theory to the technology acceptance model. Supporting employees' intentions to use e-learning systems", Educational Technology and Society, Vol. 14 No. 4, pp. 124-137.

Lee, J.-H. and Song, C.-H. (2013), "Effects of trust and perceived risk on user acceptance of a new technology service", Social Behavior and Personalitv: An International Iournal, Vol. 41 No. 4, pp. 587-597.

Lindell, M.K. and Whitney, D.J. (2001), "Accounting for common method variance in cross-sectional research designs”, Journal of Applied Psychology, Vol. 86 No. 1, pp. 114-121.

Lowe, B. and Alpert, F. (2015), "Forecasting consumer perception of innovativeness", Technovation, Vol. 45-46, pp. 1-14.

McFarlin, D.B. and Sweeney, P.D. (1992), "Distributive and procedural justice as predictors of satisfaction with personal and organizational outcomes", Academv of Management Iournal, Vol. 35 No. 3, pp. 626-637.

McKinsey and Company (2018), "There's No Place Like [A Connected] Home: perspectives on the connected consumer in a world of smart devices", Industry report. www.mckinsey.com/ spContent/connected_homes/index.html (accessed 4 May 2018).

Ma, Q. and Liu, L. (2004), "The technology acceptance model: a Meta-analysis", Lournal of Organizational and End User Computing, Vol. 16 No. 1, pp. 59-72.

Mi, J.N. and Kim, S.J. (2010), "Factors influencing the user acceptance of digital home services", Telecommunications Policy, Vol. 34 No. 11, pp. 672-682. 
Moon, J. and Kim, Y. (2001), "Extending the TAM for a world-wide-web context", Information and Management, Vol. 38 No. 4, pp. 217-230.

Moore, G.C. and Benbasat, I. (1991), "Development of an instrument to measure the perceptions of adopting an information technology innovation”, Information Systems Research, Vol. 2 No. 3, pp. 192-222.

Mun, Y.Y., Jackson, J.D., Park, J.S. and Probst, J.C. (2006), "Understanding information technology acceptance by individual professionals: toward an integrative view", Information and Management, Vol. 43 No. 3, pp. 350-363.

Park, Y. and Chen, J.V. (2007), "Acceptance and adoption of the innovative use of smartphone", Industrial Management and Data Svstems, Vol. 107 No. 9, pp. 1349-1365.

Pavlou, P.A. (2003), "Consumer acceptance of electronic commerce: integrating trust and risk with the technology acceptance model”, International Iournal of Electronic Commerce, Vol. 7 No. 3, pp. 101-134.

Podsakoff, P.M., MacKenzie, S.B., Lee, J.Y. and Podsakoff, N.P. (2003), "Common method biases in behavioral research: a critical review of the literature and recommended remedies", Journal of Abplied Psvchology, Vol. 88 No. 5, pp. 879-903.

Qi, J., Li, L., Li, Y. and Shu, H. (2009), "An extension of technology acceptance model. Analysis of the adoption of mobile data services in China", Sustems Research and Behavioral Science, Vol. 26 No. 3, pp. 391-407.

Ram, S. (1987), "A model of innovation resistance", Advances in Consumer Research, Vol. 14, pp. 208-212.

Ram, S. and Sheth, J.N. (1989), "Consumer resistance to innovations: the marketing problem and its solutions", Journal of Consumer Marketing, Vol. 6 No. 2, pp. 5-14.

Ring, P.S. and Van de Ven, A.H. (1994), "Developing processes of cooperative inter-organizational relationships", Academy of Management Review, Vol. 19 No. 1, pp. 90-118.

Röcker, C. (2010), “Why traditional technology acceptance models won't work for future information technologies?", World Academy of Science, Engineering and Technology, Vol. 41, pp. 199-205.

Rogers, E.M. (2003), Diffusion of Innovations, Free Press, New York, NY.

Schepers, J. and Wetzels, M. (2007), "A Meta-analysis of the technology acceptance model: investigating subjective norm and moderation effects", Information and Management, Vol. 44 No. 1, pp. 90-103.

Sheng, H., Nah, F.F.H. and Siau, K. (2008), "An experimental study on ubiquitous commerce adoption: impact of personalization and privacy concerns", Lournal of the Association for Information Sustems, Vol. 9 No. 6, p. 344.

Shih, T.-Y. (2013), "Determinates of consumer adoption attitudes: an empirical study of smart home services", International Journal of E-Adoption, Vol. 5 No. 2, pp. 40-56.

Straub, D., Keil, M. and Brenner, W. (1997), "Testing the technology acceptance model across cultures: a three country study", Information and Management, Vol. 33 No. 1, pp. 1-11.

Tung, F.C., Chang, S.C. and Chou, C.M. (2008), "An extension of trust and TAM model with IDT in the adoption of the electronic logistics information system in HIS in the medical industry", International Journal of Medical Informatics, Vol. 77 No. 5, pp. 324-335.

Venkatesh, V. and Davis, F.D. (2000), "A theoretical extension of the technology acceptance model: four longitudinal field studies”, Management Science, Vol. 46 No. 2, pp. 186-204.

Venkatesh, V., Thong, J.Y. and Xu, X. (2016), "Unified theory of acceptance and use of technology: a synthesis and the road ahead", Lournal of the Association for Information Sustems, Vol. 17 No. 5 , pp. 328-376.

Venkatesh, V., Morris, M.G., Davis, G.B. and Davis, F.D. (2003), "User acceptance of information technology: toward a unified view", MIS Quarterly, Vol. 27 No. 3, pp. 425-478. 
Ward, R. (2013), "The application of technology acceptance and diffusion of innovation models in healthcare informatics", Health Policy and Technology, Vol. 2 No. 4, pp. 222-228.

Wells, J.D., Campbell, D.E., Valacich, J.S. and Featherman, M. (2010), “The effect of perceived novelty on the adoption of information technology innovations: a risk/reward perspective", Decision Sciences, Vol. 41 No. 4, pp. 813-843.

Wu, J.H. and Wang, S.C. (2005), "What drives mobile commerce? An empirical evaluation of the revised technology acceptance model", Information and Management, Vol. 42 No. 5, pp. 719-729.

Wu, J.H., Wang, S.C. and Lin, L.M. (2007), "Mobile computing acceptance factors in the healthcare industry: a structural equation model", International Iournal of Medical Informatics, Vol. 76 No. 1, pp. 66-77.

Yang, H., Yang, H., Lee, H., Lee, H., Zo, H. and Zo, H. (2017), "User acceptance of smart home services: an extension of the theory of planned behavior", Industrial Management and Data Systems, Vol. 117 No. 1, pp. 68-89.

Yi, M.Y., Fiedler, K.D. and Park, J.S. (2006), "Understanding the role of individual innovativeness in the acceptance of IT-based innovations: comparative analyses of models and measures", Decision Sciences, Vol. 37 No. 3, pp. 393-426.

Zhou, Y. (2008), "Voluntary adopters versus forced adopters: integrating the diffusion of innovation theory and the technology acceptance model to study intra-organizational adoption", New Media and Societv, Vol. 10 No. 3, pp. 475-496.

Corresponding author

Marco Hubert can be contacted at: mah@mgmt.au.dk

For instructions on how to order reprints of this article, please visit our website: 